\title{
La educación democrática en la construcción de cultura de paz en Colombia
}

José Aladier SAlinas Herrera*

\section{Introducción}

Pensar en la construcción de una cultura de paz en Colombia es una tarea compleja, debido a la violencia política dada durante buena parte del siglo xx y lo que va del siglo xxi. Sin duda, se requiere aunar esfuerzos que contribuyan a la consolidación de una paz democrática, que integre, a la vez, justicia social y cultural, en los términos de Boaventura de Sousa Santos (2017). Construir una cultura de paz es un proceso posible a partir de una educación en y para la vida democrática, la cual, según Vicenç Fisas (2011), requiere de estrategias que permitan desenmascarar la violencia cultural y el patriarcado, posibilitar la disidencia, el inconformismo y el desarme cultural, afianzar un pensamiento crítico frente a lo social, a lo cual se debe sumar la reflexión ética y el compromiso moral como principios de acción necesarios para lograr una transformación social duradera. Todo este propósito es viable en el marco de una educación que procure la formación de

* Doctor en Cultura y Educación en América Latina, Universidad de Artes y Ciencias Sociales, Santiago de Chile. Magíster en Literatura de la Pontificia Universidad Javeriana. Especialista en Comunicación Educación de la Universidad Central. Actualmente es docente e investigador de la Facultad de Comunicación Social de la Universidad Santo Tomás, Sede Bogotá. 
nuevas generaciones bajo una cosmovisión pacifista, que integre lo político como dimensión y esencia de la interacción social y fundamento de toda ciudadanía participativa.

Así entonces, una educación para la paz se fundamenta en una pedagogía orientada a la resignificación de la cultura política, cuyo eje sea la formación de un sujeto político capaz de promover una sociedad democrática, de participar en la construcción permanente de un orden social cohesionado y de expresar en todo momento compromiso con el bien común. A este propósito corresponde la tarea de identificar y fundamentar los elementos de una educación para la alteridad, con base en estrategias de aprendizaje para el reconocimiento del otro, de su identidad, para valorar la opinión propia y ajena; es decir, un proceso educativo dialógico orientado al reconocimiento básico del otro como persona, a la comprensión de sus necesidades y razones de su actuar, y optar, a la vez, por aquello, material y cultural, que conviene a todos. "Tal actitud dialógica genera sin duda, no solo tolerancia, sino preocupación activa; no solo respeto, sino también solidaridad" (Cortina, 1993, p. 205).

Una educación para la paz es posible a través del vínculo necesario entre el lenguaje y el estatuto de la politeia, de la ciudadanía. El lenguaje es el más importante medio de conocimiento que tiene el ser humano y conocer es una tarea constructiva, hermenéutica, que incluye la posibilidad de nuevos sentidos de la realidad, de la historia, de la interacción con los demás, es decir, de lo político. El lenguaje permite la expresión del sentido de lo político, sustentado, a su vez, en la capacidad discursiva y argumentativa del individuo, en el diálogo, pues la política surge del encuentro entre los hombres, de la convivencia entre diferentes (Arendt, 1998), y se establece como relación, se expresa como sentido, se vive con el otro en el encuentro.

Frente a la realidad sociopolítica que vive el país, la educación constituye una oportunidad para restituir o crear un tejido social inclusivo. Con ello, se reconoce la importancia de vincular al discurso educativo y pedagógico las nuevas formas de cohesión política, de organización social, de expresión cultural, de comunicación, etc., pues los formatos preestablecidos de un modelo de sociedad, a los que se ajusta la educación tradicional, no corresponden a las nuevas realidades existentes a nivel local y mundial. 
A continuación, se abordan algunos de los componentes teóricos y pedagógicos necesarios para la construcción de una cultura de paz, posible desde una educación democrática y ciudadana.

\section{La educación democrática en Colombia}

Con base en la noción de cultura política se han estudiado diversos fenómenos, temas, problemas amplios relacionados con la socialización política. La construcción y vivencia de la cultura política se relaciona directamente con la definición de la identidad individual y social de los sujetos. Norbert Lechner (1990) señala la concepción de subjetividad en relación con el mundo cultural y valorativo de los sujetos participantes en la vida política; con ello, reconoce que toda relación con el poder se da en la cotidianidad, pues día a día se evidencian actitudes en torno al ejercicio de la autoridad, así como comportamientos de obediencia social o ciertos rechazos al poder y al orden establecido.

El estudio de la educación democrática en Colombia se ha realizado alrededor del concepto de cultura política. En efecto, desde mediados del siglo xx este concepto fue concebido como una categoría útil para el estudio y comprensión del funcionamiento de las democracias occidentales, de ahí la cercanía de la ciencia política con la sociología funcionalista, estructural funcionalista y la sicología de corte conductista. Posteriormente, el concepto fue utilizado en estudios que buscaron verificar el grado de legitimidad y eficacia de la democracia participativa. Por demás, como concepto, la cultura política tiene varias acepciones y responde a varias tradiciones teóricas:

Desde la segunda mitad de los ochenta en América Latina, y un poco más tardíamente en Colombia —más o menos desde finales de esa década y comienzos de los 90-, algunos sectores intelectuales y círculos de opinión empezaron a utilizar ampliamente la noción de "cultura política", motivados, entre otras cosas, por las circunstancias históricas de la época y el interés de los analistas 
por comprender los cambios al interior de las sociedades en transición democrática. (López de la Roche, 2000, p. 94)

López de la Roche (2000) expone, además, que la cultura política se relaciona con la identidad o identidades, sean nacionales, étnicas, sociales, regionales, locales, sexuales, de género, etarias, etc., en un momento en el que se reconocen actitudes y contextos "posmodernos", mediante los cuales se ha hecho visible la diversidad sociocultural y cada vez menos posible el hecho de subsumirla en los llamados macrosujetos clásicos de la emancipación (el proletariado o el campesinado) que han estallado como formas únicas y unívocas de representación política de la sociedad, en medio de la crisis y replanteamiento de las grandes narrativas de la modernidad.

Desde la perspectiva de construcción de cultura política, en Colombia se han estudiado los procesos de socialización y formación democrática en la escuela. En el trasfondo de los modelos tradicionales de educación implementados en el país se reconoce el peso de la civic culture $^{1}$ : se ve en los lineamientos del sistema educativo nacional, en los planes sectoriales de educación, en las estrategias pedagógicas de aula y en los estudios evaluativos sobre la cultura política. Para López de la Roche (2000):

La tradición teórica de la "civic culture" además de su notoria naturaleza euro-norteamericana-céntrica, institucionalista y universalista, deja por fuera aspectos histórico-culturales fundamentales en el análisis político-cultural, y desde el punto de vista metodológico,

1 Es una de las tradiciones más difundidas en el estudio de la cultura política, la cual fue desarrollada en la investigación politológica norteamericana. Como modelo de estudio de la cultura política, se gestó en los marcos de la teoría estructural funcionalista de la modernización y de la transición de sociedades tradicionales a sociedades modernas. Igualmente, la perspectiva de la civic culture corresponde a una tradición en la investigación en cultura política, el método privilegiado de análisis son las encuestas y las escalas de actitud, con las cuales se intenta medir y cuantificar el desarrollo o subdesarrollo de la cultura política en la sociedad. 
la prioridad conferida a la intención cuantificadora sobre la base de la aplicación de las encuestas y escalas de actitud, reduce sustancialmente la posibilidad de dar cuenta de otras facetas del fenómeno a través de otras herramientas, más vinculadas a la investigación cualitativa y a la intención interpretativa. (p. 108)

La tradición de la cívic culture ha marcado la educación democrática en el país, lo cual ha incidido en el desconocimiento del contexto sociocultural escolar y en la transmisión de un modelo de sociedad preestablecido en la formación ciudadana. Esta tradición no responde a la conformación de la cultura política de hoy, que tiene una lógica más amplia, pluralista, cuyos procesos formativos deben trascender el escenario escolar y deben integrar todos aquellos espacios en donde actualmente se modelan las identidades colectivas e individuales.

Ahora bien, frente a la construcción de cultura democrática en la educación colombiana se han realizado varias investigaciones. Varios de estos trabajos ${ }^{2}$ coinciden en una postura crítica sobre esta educación, la del periodo posterior a la promulgación de la Constitución de 1991 y de la Ley General de Educación, expedida en 1994. Los estudios cuestionan diversos aspectos del marco normativo y los modelos educativos consecuentes, entre ellos, la centralidad en un modelo único de cultura política en el que se privilegian los elementos de toda democracia representativa; el hecho de simplificar el tema de la educación democrática escolar alrededor del respeto por el orden y la norma. Asimismo, se preguntan por la pertinencia y eficacia de las políticas

2 Se hace referencia a los siguientes trabajos: 1) De la educación democrática a la educación ciudadana: una década de incertidumbres, estado del arte realizado en el 2006, Universidad Pedagógica de Bogotá y el Instituto para la Investigación Educativa y el Desarrollo Pedagógico (IDEP). 2) "Educación para la democracia y la formación política en Colombia: 1980-2006”, realizado por Alejandro Peláez y Diego Márquez para la fundación Konrad Adenauer (entidad alemana de orientación católica). 3) "El gobierno escolar y educación ciudadana. Estudio de casos”, desarrollado por Humberto J. Cubides C. Universidad Central, Instituto para la Investigación Educativa y el Desarrollo Pedagógico (IDEP), Compensar y Colciencias. 
educativas internacionales implementadas en el país, y la aplicación de modelos de evaluación de estos aprendizajes mediante estándares que dan prelación a metodologías que reafirman la cultura cívica tradicional. En fin, según los estudios, el modelo de educación ciudadana escolar asume un paradigma preestablecido de ciudadano:

Los atributos morales de los sujetos ciudadanos son definidos antes de reconocer la experiencia de los jóvenes, es decir, se diseña un formato moral y políticamente adecuado al cual deben adaptarse los jóvenes para recibir una valoración (evaluación) positiva o negativa en torno a su formación política y ciudadana. (Herrera, Pinilla, Infante y Díaz, 2005, p. 133)

Con ello, los procesos escolares no visibilizan los trayectos existenciales de los estudiantes, más aún, se desconocen y emplazan por formas de subjetividad y modos de vida predeterminados por el sistema educativo. Así, se ha generado una disociación entre el propósito educativo democrático y la realidad social y cultural de los sujetos, sin que en ello, hasta el momento, medie una reflexión pedagógica y, menos, un diálogo con la realidad social y cultural extraescolar.

En cuanto al gobierno escolar, creado por la Ley General de Educación como estrategia de participación de la comunidad educativa (alumnos, docentes, padres de familia), en general, estos trabajos señalan que no ha logrado sus propósitos iniciales, por estar centrado en un modelo único de democracia representativa. Con ello, la escuela evidencia las usuales paradojas y contradicciones entre la democracia representativa y la participativa, agravada por la obligatoriedad escolar de responder a la normativa. De esta manera, el énfasis en los procesos de representatividad y la débil formulación de vías para posibilitar la participación estudiantil, deja al gobierno escolar como una estrategia más cercana a una versión liberal de la ciudadanía, simplificada como un ejercicio de derechos, en este caso, de representación.

En consecuencia, es posible afirmar que la educación democrática y ciudadana en Colombia, en perspectiva de paz, no ha abordado 
una política de vida como propósito formativo. En otras palabras, las estrategias educativas para desarrollar cultura democrática han sido subutilizadas, pues han respondido a viejas doctrinas políticas, a lineamientos internacionales y a prácticas pedagógicas funcionalistas. Por ello, la construcción de cultura democrática en Colombia constituye un desafío, no solo por el momento de transición política que vive el país, sino por la ausencia de un modelo de educación democrática y ciudadana que responda a los retos que plantea hoy la realidad social, cultural y política.

\section{La ciudadanía como expresión democrática}

Es posible afirmar que la educación democrática se ha basado en una concepción despolitizada de la ciudadanía, evidente en el carácter individualista que emerge del modelo de ciudadano implementado en la vida escolar. La concepción de ciudadano presente en los lineamientos educativos nacionales responde, en términos generales, a los principios del liberalismo. Precisamente, para Mercedes Oraisón (2005), el liberalismo postula una idea de Estado neutral comprometido únicamente con la protección de las autonomías individuales. Dicha autonomía, sin embargo, permite que cada persona forje su identidad con el concurso de los otros, siempre y cuando este apoyo sea significativo en el propósito individualista. Frente a esta circunstancia, la autora argentina señala la necesidad de reafirmar la noción moral de la autonomía como fundamento de toda libertad jurídicopolítica del ciudadano. Así, la ciudadanía debe sustentarse en un sentido ampliamente político, en el que se despliegue no solo la relación del individuo con los demás, sino también la relación del ciudadano con los diferentes tipos de organizaciones de la sociedad civil.

Se propone aquí, en el marco de una educación para la paz, la necesidad de pensar en una nueva alfabetización ciudadana que integre la formación de la subjetividad política. Para Boaventura de Sousa Santos (1998) la subjetividad política constituye el espacio por excelencia para la producción de sentido, en este caso, sentido 
político, sobre el cual los sujetos construyen realidades posibles o buscan transformar las existentes; así, en la configuración de la subjetividad política se integran el conocimiento, la producción simbólica, el manejo de los saberes, el tejido social y la imaginación de mundos más justos.

Por tanto, revalorar lo político como dimensión esencial en la construcción de la subjetividad del ciudadano es una estrategia educativa necesaria en una sociedad individualista, en la que la fuente de unión e integración ya no es el bien común, sino el miedo, la sospecha y el odio. Una sociedad en donde la amistad y la solidaridad, que siempre fueron esenciales en la vida comunitaria, se volvieron muy frágiles, en un mundo completamente inestable.

En este sentido, educar en la dimensión política al sujeto es darle al ciudadano los elementos necesarios para la cohesión social, desde la cual haga frente al miedo instalado en la sociedad contemporánea; pues el temor es hoy la única manera de lograr la solidaridad colectiva, y la angustia social nos lleva a identificar enemigos comunes. Bauman (2007) habla de Sicherheit, concepto alemán cuya traducción requiere tres vocablos: seguridad, certeza y protección, ausentes en la sociedad actual. Vivir en la incertidumbre parece actualmente un estilo de vida, como la única manera posible de vivir el modelo de sociedad creado por la economía, el mercado y la violencia.

Repolitizar la ciudadanía en la educación democrática significa afirmar, con Hannah Arendt (2001), que la política hace parte de la vida de todos los hombres, que la vida humana no solo integra el ciclo biológico, sino que se desarrolla en el ámbito de la acción política. El individuo como actor político sería aquel que se atreve a salir de la oscuridad de lo privado para enfrentarse con sus semejantes y ejercer su libertad de manera creativa y ética. La acción política correspondería, en términos de Arendt, a la vida activa, pero su origen está en la vida del espíritu, pues en ella está la posibilidad de imaginar y crear el mundo, no solamente vivirlo de forma pasiva. Si la condición humana se define desde la pluralidad y la diferencia, la condición política es un ejercicio dialéctico entre la vida activa y la vida contemplativa — la vida del espíritu-, esto es, una vivencia posible en la libertad del ser humano. 
Lo político tiene un carácter discursivo, aspecto relevante en el pensamiento de Platón y Aristóteles, quienes centraron la preocupación de lo político en el manejo de la palabra a través de un arte eminentemente público: la retórica. El buen retórico es aquel capaz de provocar desorden, pérdida de sentido, o bien ofrecer una alternativa para recuperar el orden o, en el mejor de los casos, crear un nuevo sentido. Para Foucault (1970), por su parte, el discurso no es simplemente aquello que traduce las luchas o los sistemas de dominación, sino aquello por lo que, y por medio de lo cual se lucha, aquel poder del que se quiere ser dueño. Así, en relación con el poder, en la base del discurso político se encuentra la disputa por el sentido, es decir, una lucha de intereses de donde emerge el conflicto, por tanto:

Las expresiones del quehacer político serían primero que todo la manifestación de una dinámica intrínseca que tiene como motor el conflicto, la disputa. Esta a su vez, no se entendería solamente como el conjunto de acciones de unos bandos o personas contra otros, sino como el resultado de un litigio permanente por el sentido y finalidad de la vida social. (Salinas y Stange, 2009, p. 139)

Ahora, para hacer parte del litigio se requieren capacidades que posibiliten en el sujeto participante la indagación crítica, el diálogo, la expresión de ideas, el debate y el encuentro de experiencias diversas en el plano cultural y social. Es fundamental, además, reconocer el espacio de lo político (es decir de lo público) como un terreno en el cual se manifiestan los términos, las gramáticas, los sujetos y los objetos de la disputa política.

Sin embargo, lo político no se define exclusivamente por la discursividad; es la inscripción de tal o cual esfera discursiva en un conjunto de gramáticas y subjetividades que, una vez legitimadas, producen las condiciones para la disputa política. Por tanto, es importante conocer los sujetos y las prácticas que hacen posible lo político, la producción de sentido que habilita el acceso a un discurso en el cual se establece el objeto del litigio que, a su vez, busca movilizar representaciones, imaginarios, para generar acciones específicas. Las condiciones de 
producción y reconocimiento de lo político, de naturaleza no discursiva, pueden generar tensiones y reconocimiento de lo político mediante la fuerza o la suspensión transitoria de ciertos derechos.

Para Salinas y Stange (2009), la sintaxis de lo político se expresa en sujetos, rituales y actos productores de lo político, lo cual se constituye en la emergencia de un ethos propio para cada espacio de disputa. Estos ethos se puede identificar de manera diferente "en cada época histórica", o mejor "en cada momento histórico", verbigracia, durante la antigüedad está circunscrito a la retórica, espacio restringido a los iguales antes que abierto a todos los hombres; y en la época moderna se constituye, en parte, desde el reconocimiento de una supuesta igualdad normativa de los desiguales, de los ciudadanos como sujetos considerados libres.

En la actualidad, según lo expuesto por Salinas y Stange (2009), lo mediático constituye el espacio de reconfiguración del ethos político moderno. Lo anterior, porque los medios masivos y las tecnologías de la comunicación implican una redefinición de las prácticas políticas, con lo cual se presenta una progresiva reconversión de la mediación de lo público en mediatización pública, y en donde la forma predominante está sujeta al actual régimen visual. Así, la retórica política ya no se limita al ámbito del discurso oral, aparece escrita en la prensa, como imagen en los medios audiovisuales y como gesto en el montaje, el color y la sonoridad televisiva. De hecho, los nuevos medios — sobre todo la televisión y el internet- constituyen los espacios para visibilizar la disputa por lo político.

En estos nuevos escenarios de litigio por el sentido, se integran los temas clásicos inherentes al debate político: la libertad, el orden, la seguridad, la soberanía, la nacionalidad, la representatividad, etc., de esta manera, lo mediático hizo de lo político un espectáculo. Por lo demás, las formas de la expresión dadas en los formatos novedosos de los medios cobran fuerza política; en otras palabras, en la actualidad lo político no es solo el discurso, lo disputado, sino el modo mismo del litigio (Salinas y Stange, 2009).

Ahora bien, si lo político se relaciona con la capacidad discursiva y la argumentativa, y la moral, por su parte, se enseña para orientar la acción del sujeto, entonces ambos aspectos son fundamentales en la 
educación del ciudadano. En la discusión contemporánea acerca del conocimiento de la moral y de los motivos de la acción humana, el tema de la sensibilidad moral desempeña un papel central. Guillermo Hoyos (2000) señala que en la relación entre la sensibilidad moral y las diversas formas de argumentación ética y moral está la base de una ética para ciudadanos, la cual debe incluir, según el autor, la formación de la persona moral a partir de las vivencias en las que se dan los fenómenos morales en el mundo, y de la manera como son asumidos comunicativamente los sentimientos morales. Aunque no es fácil ubicar y caracterizar, de forma unívoca, la problemática de la relación entre ética y política a nivel de lo educativo (o de lo cultural), es relevante en el caso de la educación ciudadana, pues la capacidad argumentativa y discursiva que caracteriza a lo político tiene relación con el ámbito de la moral y la ética, de lo contrario, afirma Hoyos (2000), el campo de la política quedaría convertido en realpolitik.

Ahora, una ética para ciudadanos, en los términos del profesor Hoyos, no se limita a rehabilitar la urbanidad, como urbanitas - propia de quienes viven en la urbe-; dicha urbanidad siempre debe ser entendida en un marco más amplio de perfiles éticos y políticos, desde los cuales se deja sin peso a quienes siguen proclamando métodos autoritarios de educación ciudadana (autoritarismo dogmático), que "forma ciudadanos intolerantes, se encuentren estos en las mayorías o reclamen privilegios a título de ser minorías" (Hoyos, 1998, p. 296).

Educar para la ciudadanía requiere, entonces, de una educación ética, de una formación moral que posibilite la discusión y expresión de las convicciones morales que traen los estudiantes. Es necesario desarrollar la sensibilidad moral, aspecto relevante dentro de la fenomenología de lo moral (Hoyos, 1998), para estar en capacidad de detectar y vivenciar los conflictos —en el orden moral - tal como se presentan a diario en la sociedad civil. Toda sociedad espera que sus miembros reconozcan los diferentes tipos de relaciones sin necesidad alguna de coacción, pues es en estos contextos de interacción en los que se confrontan consensos y disensos, en donde se aprende a respetar a quien disiente, a reconocer que los demás tienen sus propios puntos de vista, sin necesariamente tener que compartirlos. 
Es importante tener en cuenta en el proceso educativo todo el problema de la sensibilidad moral. El fomentarla, formarla, sin caer en moralismos extremos, pero destacando los comportamientos ciudadanos, es labor tanto de la familia como de la escuela, advirtiendo que normalmente esta última cuenta con mejores elementos teóricos y con situaciones existenciales más complejas y ricas para lograrlo. (Hoyos, 1998, p. 298)

La educación, sin embargo, debe procurar un aprendizaje que permita el paso del ámbito personal al colectivo, a partir de un principio dialogal, en el marco ético y moral de la sociedad. Así, integrar la fenomenología de lo moral a la educación ciudadana constituye una estrategia para que cada estudiante comprenda "cómo la moral se ocupa de sentimientos y experiencias concretas, así tenga que expresarse no en sentimientos, sino en juicios y principios" (Hoyos, 1998, p. 297). En fin, la educación es el momento de la vida para que el sujeto adquiera los fundamentos de una ciudadanía abierta a la interculturalidad y al pluralismo, a la cooperación y la organización social.

\section{Hacia una pedagogía para la democracia y la paz}

Desde el punto de vista pedagógico, una educación comprometida con la vida democrática, la ciudadanía y la paz genera incertidumbre, inquietud y preguntas sobre aspectos esenciales, por ejemplo, ¿de qué manera educar en la autonomía, en la libertad, en la ley, en la autoridad? Educar en la autonomía, como rasgo esencial de una ciudadanía participativa y activa, evidencia varias tensiones inherentes desde el punto de vista pedagógico. Una de estas tensiones corresponde a la autoridad del docente frente a la comprensión y experimentación de la libertad por parte del alumno. De acuerdo con Tassin (2013), la meta para el alumno es elevada, pues debe trabajar en conducirse a sí mismo, en la relación que establece con otros, pero también en una obediencia que no debe ser servidumbre, con independencia de espíritu y acción, de cuyo éxito y logro depende el aprendizaje de 
la coexistencia social y política como fundamento de realización de cada individuo.

Toda labor educativa para la vida democrática está llamada a promover la comprensión de la validez universal de la ley y el beneficio que esta otorga al bien común, sin que dicha comprensión se fundamente en un criterio de voluntad personal o autoritarismo dogmático. En realidad, estos interrogantes muestran algunas limitantes en la educación ciudadana que, de no atenderse, pueden llevar al fracaso educativo. De ahí la importancia de generar un pensamiento crítico en la construcción democrática, a partir de un auténtico compromiso político y ciudadano.

Todo compromiso político parte del respeto a la ley; es lo que justifica educar en la validez universal de la ley, interpretar el beneficio que esta otorga al bien común, sin que la comprensión se fundamente en un criterio de voluntad personal y autoritaria de un docente. Ahora, educar en la ley implica, por un lado, la relación con las condiciones sociales, económicas y culturales; y, por otro, la formación de la autonomía. Así, la educación se orienta a la formación de un sujeto autónomo, quien, como ciudadano, sabrá entonces gobernarse, aún frente a la corrupción de los otros.

La educación democrática no puede basarse en la coerción docente. Recurrir a estos mecanismos de imposición expresa ausencia de autoridad. No obstante, debe haber claridad sobre el sujeto que se quiere formar como ciudadano en la actualidad, especialmente en esta sociedad de riesgo e incertidumbre producida por la economía y la inestabilidad política. Precisamente, Martha Nussbaum (2012) ha expuesto el carácter contraproducente de las instituciones de enseñanza orientadas por la lógica rentable y por el afán de producir un homo economicus, definido solamente por su función laboral. Por su parte, Tassin (2013) señala los resultados nefastos de una educación orientada a la fabricación de seres funcionales al sistema económico y de mercado. Desde esta perspectiva, el docente que pretende educar para la democracia y la paz tiene dos caminos posibles: cumplir la tarea del formateo industrial de seres conformes y funcionales en el seno de una economía generalizada y de necesidades sociales; o trabajar por el libre aprendizaje de una libertad de pensar y actuar. 
Sin embargo, resulta interesante y paradójico a la vez la interpelación de Tassin (2013) acerca de la tarea educativa sobre la libertad, a nivel escolar:

¿Cómo una institución coercitiva, para la cual la autoridad ha dejado de ser un motivo de respeto, puede formar sujetos libres? ¿Cómo un ser triplemente dependiente, por su insuficiencia, con respecto a sus padres; por su ignorancia, con relación a sus maestros; y por su minoría, con respecto a la sociedad entera, puede ser llevado a hacer la experiencia de su libertad? Y en el contexto de la ciudadanía ¿cómo puede ser llevado a hacer de la experiencia de su libertad aquello que lo obliga al respeto a los otros? (p. 21)

Educar para la ciudadanía debe ser un ejercicio constante de aprendizaje sobre la libertad, basado en el reconocimiento de la libertad de los demás. El aprendizaje de la libertad es el aprendizaje del vínculo con el otro en la libertad. "Únicamente ese vínculo de la libertad, esa obligación hacia la libertad del otro que me impone mi propia libertad, puede llevar dignamente el nombre de ciudadanía" (Tassin, 2013, p. 22). La libertad, entonces, entraña no solo el ejercicio de la liberación, sino la responsabilidad, la obligación, con la libertad del otro.

En el marco de los cambios profundos que vive la sociedad actualmente, hay una obligación de aprender a vivir juntos, lo que implica conocer mejor a los demás, su historia, su cultura y sus tradiciones. Esta preocupación se expone en varios documentos internacionales como el informe de la Unesco sobre los logros de la educación. Alicia Tallone (2010), para el caso, señala que en el desarrollo de los sistemas democráticos en América Latina, la educación tiene un papel importante en dar forma y sentido a las interacciones entre los ciudadanos, puesto que en sus procesos está la posibilidad de crear las condiciones necesarias para construir una auténtica cultura democrática. Para ello es necesario sobrepasar el currículo centrado en la educación cívica, en conocimientos y deberes, para construir otro en el cual la cultura ciudadana se centre en la participación y la responsabilidad de cada persona. 
La escuela tiene hoy la posibilidad de hacer que los valores democráticos se instalen tempranamente en el universo cultural de las nuevas generaciones. La idea de una democracia, más allá del funcionamiento formal de las instituciones gubernamentales y los sujetos en el poder, contempla la necesidad de consolidar una sociedad que se fundamente ampliamente en la convivencia pacífica. Para el logro de este fin, es necesario apostar por el paso de una educación cívica tradicional a una educación para la ciudadanía activa, que exige la ampliación de esta noción a los aspectos sociales, políticos y culturales de quienes asumen el proceso de aprendizaje democrático.

El actual contexto político mundial reclama más democracia, más procedimientos que garanticen una participación autónoma y racional y, a la vez, la creación de instancias y espacios deliberativos y de toma de decisiones, que permitan incorporar en estos procesos a amplios sectores de la sociedad.

Educar para la paz requiere de un comenzar, es decir, de un nuevo camino en la pedagogía, cuya particularidad esté dada en el vínculo con lo político, con una práctica de liberación permanente; pues, como afirma Rancière (2014), "quien enseña sin emancipar, embrutece” (p. 32). Así, el aprendizaje debe ser un acto permanente de libertad, no puede estar, por tanto, subordinado a viejas estructuras intelectuales que no favorecen la construcción de un pensamiento nuevo. El docente debe explicar menos bajo su propia lógica, y permitir más la comprensión de los hechos por parte de los estudiantes:

El secreto del maestro es saber reconocer la distancia entre la materia enseñada y el sujeto a instruir, como así también la distancia entre aprender y comprender. El explicador es quien plantea y da por abolida la distancia, quien la despliega y la reabsorbe en el seno de su palabra. (Rancière, 2014, p. 19)

De esta manera, cada estudiante puede comprender el mundo, la realidad, la historia; ser un sujeto capaz de producir nuevos sentidos y establecer nuevas maneras de relación con los otros, para superar las viejas estructuras. El comprender, como acto pedagógico, se vincula 
a una alfabetización ciudadana, entendida, más allá de una habilidad técnica, como apertura hacia el universo simbólico de lo político. Una alfabetización que, alejada de cualquier perspectiva tecnocrática, vincule la competencia lingüística con la adquisición de habilidades para la lectura, el análisis y la argumentación.

En otras palabras, es necesaria una alfabetización que incremente el universo cultural y abra nuevas oportunidades de acceso a los capitales simbólicos de lo político. La adquisición de estos capitales es determinante para controvertir las estructuras y jerarquías de poder que se encuentran detrás de la inequidad y la desigualdad social. La transformación de la realidad educativa está dada en la posibilidad de una alfabetización ciudadana crítica, para que cada joven comprenda las posibilidades de transformación social, y de oportunidades, en el marco de una ciudadanía activa y participante, que promueva formas pacíficas de entendimiento.

No cabe duda de que el actual contexto político mundial reclama más democracia, más procedimientos que garanticen la participación autónoma y racional; como también instancias y espacios deliberativos y de toma de decisiones, que permitan incorporar en estos procesos a amplios sectores de la sociedad. La escuela es un escenario potente para que las nuevas generaciones accedan a la cultura de participación ciudadana. En este sentido, Tallone (2010) afirma que "promocionar los valores que estarían en la base para conformar sociedades democráticas y plurales, puede ser un importante vector para orientar la función de la escuela" (p. 157). La convivencia no es una dificultad en la vida escolar; es una oportunidad de crecimiento, de conocimiento, de comprensión y vivencia de la norma, de la ley, de promover la regulación pacífica de los conflictos y aprender a fortalecer los vínculos sociales a temprana edad.

\section{Conclusiones}

La construcción de una cultura democrática, como contexto de paz, ha sido una preocupación educativa permanente en la historia del país. Sin embargo, frente a la transición política que vive Colombia es necesaria 
una educación para la paz — democrática — que consolide una sociedad civil fuerte políticamente. La escuela, entonces, es el territorio idóneo para la construcción de la subjetividad política.

La educación democrática tiene como eje la comprensión de la política como parte esencial en la vida de todos los hombres. En este caso, la acción pedagógica estaría centrada en procurar la comprensión de la libertad como el rasgo político esencial del ser humano.

Desde el reconocimiento de lo político como dimensión relevante de la vida social, se entiende que la persona, siendo un ser con otros, es un ser de logos, de lenguaje y, por tanto, un constructor de discurso. La posibilidad del discurso es determinante en el hecho de vivir juntos, es decir, es fundamento de lo político. La vida en común permite entender que los hombres están en capacidad de superponer los ámbitos privados de pertenencia, para entrar en el umbral de lo público, en donde convergen diversos puntos de vista sobre la misma realidad que se comparte.

Ahora, toda visión del mundo se construye conjuntamente, en la medida en que el hombre fabrica cosas (materiales o no), las comparte y las percibe desde perspectivas diferentes. A partir de esta experiencia surge la posibilidad de establecer acuerdos válidos políticamente, producto de la discusión, de la pugna por el sentido. Por ello, el aprendizaje del litigio, del debate y la argumentación es fundamental en la educación política; además del aprendizaje de aquellas capacidades que posibiliten en el sujeto la indagación crítica de la realidad, el diálogo y la valoración de experiencias diversas en el plano cultural y social: aspectos pedagógicos fundamentales en toda educación para la paz.

Asimismo, la educación democrática integra, a su vez, una educación para la participación ciudadana, a partir de estrategias pedagógicas que fortalezcan la autorregulación, la autonomía, la responsabilidad, la protección de los derechos ciudadanos, la importancia de saber organizarse y asociarse, entre otros asuntos. La participación ciudadana requiere previamente educar en el concepto de lo público, entendido como aquellos bienes, servicios y transacciones que convienen a todos de la misma manera y que garantizan el respeto de la dignidad, desde los principios de la ética y la moral; requiere entender que una sociedad es más equitativa en cuanto más bienes públicos pueda construir 
y gestionar para todos; también, diferenciar lo público de lo estatal, puesto que la claridad o confusión al respecto incide en la participación ciudadana y en el valor dado a los bienes sociales comunes; y asumir que un bien público es tal porque conviene a todos de la misma manera, todos pueden acceder en la misma medida: si ese bien, que debiera ser igual para todos, provee a unos de una calidad y a otros de otra, pierde su carácter de público, venga de donde venga (Toro, 2010).

Finalmente, la educación democrática es posible con una educación escolar abierta a la realidad sociocultural y política de los estudiantes, con una pedagogía que promueva el aprendizaje de la justicia, la equidad y la paz, valores inherentes de la paz democrática.

\section{Referencias bibliográficas}

Arendt, H. (1998). Los orígenes del totalitarismo. Madrid: Taurus.

Arendt, H. (2001). ¿Qué es la política? Barcelona: Paidós.

Bauman, Z. (2007). En busca de la política. Ciudad de México: Fondo de Cultura Económica.

de Sousa Santos, B. (1998). De la mano de Alicia. Lo social y lo político en la posmodernidad. Bogotá: Siglo del Hombre Editores - Universidad de los Andes.

de Sousa Santos, B. (2017). Democracia y transformación social. Bogotá: Siglo del Hombre Editores, Siglo veintiuno editores.

Fisas, V. (2011). Educar para una cultura de paz. Quaderns de construccio de pau, (20), 2-8.

Foucault, M. (1970). El orden del discurso. Barcelona: Tusquets.

Giddens, A. (2001). Sociología (4. ${ }^{a}$ ed.). Madrid: Alianza Editorial.

Habermas, J. (1991). Ética del discurso. Notas sobre un programa de fundamentación. En Conciencia Moral y Acción Comunicativa. Barcelona: Península.

Habermas, J. (1999). Teoría de la acción comunicativa, Vol 1: Racionalidad de la acción y racionalización social. Madrid: Taurus. 
Herrera, M., Pinilla, A., Infante, R. y Díaz, C. (2005). La construcción de cultura política en Colombia. Proyectos hegemónicos y resistencias culturales. Bogotá: Universidad Pedagógica Nacional.

Hoyos, G. (1998). Ética para ciudadanos. En F. Giraldo y F. Viviescas. Pensar la ciudad. Bogotá: Tercer Mundo Editores.

Hoyos, G. (2000). Formación ética, valores y democracia. En M. Henao y J. Castro. Estados del Arte de la Investigación en Educación y Pedagogía en Colombia. Bogotá: Icfes, Colciencias, Socolpe.

Lechner, N. (1990). Los patios interiores de la democracia: Subjetividad y política. Santiago de Chile: Fondo de Cultura Económica.

Lechner, N. (2003). La transformación de la sociedad civil. En Relaciones entre Estado y Sociedad Civil. ¿Concertación o vigilancia? Lima: Calandria.

López de la Roche, F. (2000). Aproximaciones al concepto de cultura política. Convergencia. Revista de ciencias sociales, 7(22), 93-123. Recuperado de http//www.redalyc.org/articulo.oa?id=10502205

Nussbaum, M. (2012). Sin fines de lucro: por qué la democracia necesita de las humanidades. Buenos Aires: Katz.

Oraisón, M. (2005). Representaciones y prácticas de la ciudadanía, Una lectura histórico-pedagógica del caso argentino. En M. Oraisón (coord.), La construcción de la ciudadanía en el Siglo XXI. Barcelona: Octaedro y Organización de Estados Iberoamericanos.

Peña, J. (2008). Nuevas perspectivas de la ciudadanía. En F. Quesada (ed.). Ciudad y ciudadanía Senderos contemporáneos de la filosofía política. Madrid: Trotta.

Rancière, J. (2014). El maestro ignorante, Cinco lecciones sobre emancipación intelectual. Santiago de Chile: Hueders Educación.

Salinas, C. y Stange, H. (2009). Poder y Comunicación. La irresoluble tensión entre palabra, imagen y política. Revista Perspectivas de la comunicación, 2(1).

Tallone, A. (2010). El desafío de la convivencia escolar: apostar por la escuela. En B. Toro y A. Tallone (coords.), Educación, valores y ciudadanía. Madrid: Organización de Estados Iberoamericanos.

Tassin, E. (2013). ¿Qué éxito se puede esperar de un oficio imposible? En Varios autores, Memorias del Seminario Internacional. Ciudadanía y convivencia: un espacio de reflexión desde la educación y la pedagogía. Bogotá: Instituto para la Investigación Educativa y el Desarrollo Pedagógico [IDEP]. 




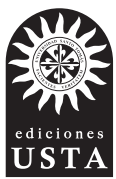

Esta obra se editó en Ediciones USTA.

Se usó papel propalcote de 280 gramos para la carátula y papel bond beige de 75 gramos para páginas internas.

Tipografía de la familia Sabón.

2019 
